Int. J. Electrochem. Sci., 14 (2019) 8058 - 8069

International Journal of

ELECTROCHEMICAL

SCIENCE

www.electrochemsci.org

\title{
Facile Synthesis of Zinc Cobaltate Nano flakes: An enhanced Electrochemical detection of Organic Pollutant 4-Nitrotoluene
}

Alagumalai Krishnapandi ${ }^{1}$, Ramachandran Rajakumaran ${ }^{1}$, Shen-Ming Chen ${ }^{1, *}$, Yi-Ling, Li ${ }^{1}$, Tse-Wei Chen ${ }^{1,2}$, Shih-Yi Lee ${ }^{3, *}$ and Wen-Han Chang ${ }^{4,5}$

${ }^{1}$ Electroanalysis and Bioelectrochemistry Lab, Department of Chemical Engineering and Biotechnology, National Taipei University of Technology, No.1, Section 3, Chung-Hsiao East Road, Taipei 106, Taiwan, ROC.

${ }^{2}$ Research and Development Center for Smart Textile Technology, National Taipei University of

Technology, Taipei 106, Taiwan, ROC

${ }^{3}$ Division of Pulmonary and Critical Care Medicine, Taitung MacKay Memorial Hospital; MacKay Memorial Hospital; Mackay Junior College of Medicine, Nursing, and Management College, Taipei, Taiwan.

${ }^{4}$ Department of Emergency Medicine, MacKay Memorial Hospital; Institute of Mechatronic Engineering, National Taipei University of Technology, Taiwan

${ }^{5}$ Graduate Institute of Injury Prevention and Control; School of Medicine, Taipei Medical University, Taiwan

*E-mail: smchen78@ms15.hinet.net, leesyi5538@yahoo.com.tw

doi: $10.20964 / 2019.08 .68$

Received: 3 March 2019/ Accepted: 22 May 2019 / Published: 30 June 2019

The current work, we have demonstrate an electrochemical determination of 4-nitrotoluene (4-NT) based on zinc cobaltate nanoflakes $\left(\mathrm{ZnCo}_{2} \mathrm{O}_{4} ; \mathrm{ZnC} \mathrm{Nfs}\right)$ The $\mathrm{ZnC} \mathrm{Nfs}$ was synthesized by simple Coprecipitation method and its physicochemical properties were systematically studied with various analytical and spectroscopic techniques such as XRD, FESEM and EDX. Moreover, the proposed ZnC Nfs modified with Screen-printed carbon electrode (SPCE) after that directly used for the electrochemical determination (4-NT). The ZnC/SPCE shows an excellent electrochemical activity for the (4-NT) detection. The as prepared $\mathrm{ZnC}$ Nfs provide a highly selective and sensitive electrocatalyst for the (4-NT) determination with good linear range response $0.05 \mu \mathrm{M}-385.5 \mu \mathrm{M}$ and low detection limit $0.044 \mu \mathrm{M}$. The $\mathrm{ZnC} / \mathrm{SPCE}$ electrochemical sensor established the outstanding selectivity, well stability and reproducibility.

Keywords: Electrochemical sensor, Organic pollutant, Co-precipitation, $\mathrm{ZnCo}_{2} \mathrm{O}_{4}$ nanoflakes, 4-NT.

\section{FULL TEXT}


(C) 2019 The Authors. Published by ESG (www.electrochemsci.org). This article is an open access article distributed under the terms and conditions of the Creative Commons Attribution license (http://creativecommons.org/licenses/by/4.0/). 